\title{
Evaluation of thermal comfort conditions in Ourmieh Lake, Iran
}

\author{
Hassan Farajzadeh • Andreas Matzarakis
}

Received: 28 April 2011 / Accepted: 13 July 2011 / Published online: 26 July 2011

(C) The Author(s) 2011. This article is published with open access at Springerlink.com

\begin{abstract}
Research in developing countries concerning the relationship of weather and climate conditions with tourism shows a high importance not only because of financial aspects but also an important part of the region's tourism resource base. Monthly mean air temperature, relative humidity, precipitation, vapor pressure, wind velocity, and cloud cover for the period 1985-2005 data collected from four meteorological stations Tabriz, Maragheh, Orumieh, and Khoy were selected. The purpose of this study is to determine the most suitable months for human thermal comfort in Ourmieh Lake, a salt sea in the northwest of Iran. To achieve this, the cooling power and physiologically equivalent temperature (PET) calculated by the RayMan model and the Climate Tourism/Transfer Information Scheme (CTIS) were used. The results based on cooling power indicate that the most favorable period for tourism, sporting, and recreational activities in Ourmieh Lake is between June and October and based on PET between June to September. In addition, the CTIS shows a detailed quantification of the relevant climate-tourism factors.
\end{abstract}

\footnotetext{
H. Farajzadeh $(\bowtie)$

Department of Geography, Humanities Faculty,

Teacher Training University,

Karaj, Iran

e-mail: hassanfa2003@yahoo.com

\section{A. Matzarakis}

Meteorological Institute, Albert-Ludwigs-University Freiburg,

Werthmannstr. 10,

79085 Freiburg, Germany

e-mail: andreas.matzarakis@meteo.uni-freiburg.de
}

\section{Introduction}

Tourism, in the present century, as an important part of the world economy is affected by weather conditions and climate. Interaction of climate, tourism, and recreation has led to a new branch of climatology, known as tourism climatology, which relies on applied climatology and human biometeorology (Matzarakis 2006, 2010). Actual information and the appropriate climate for tourists, tourism industry, tourism organizers, agents, tourism planners, and investors, especially in the period before and during the holidays and turnover are very useful and vital. Relevant climate information can be obtained through different media (tourist guide books, Internet, CD, DVD) or through weather services (Matzarakis 2006).

At several travel destinations, climate represents a natural resource on which the tourism industry is predicated. Usually, geographical location, topography, landscape, vegetation, and fauna are factors that influence decisions regarding areas to be visited. Weather and climate are two additional factors (Abegg 1996). It is a fact that weather/climate and tourism/recreation are interconnected in diverse ways. Therefore tourists, tour organizers, travel agencies, tourism planners, and stakeholders need to be reliably informed about the role of weather and climate (Matzarakis 2006). Climate is a key resource for many kinds of tourism and these factors can be measured and evaluated.

There are three tourism climate issues that are worthy of discussion: the first issue is the use of an appropriate index for tourism, the second issue is how subjective thermal perception and other factors of tourists in the tourism climate index can be included or implemented, the last issue is whether tourists prefer to visit destinations in appropriate weather and climate. This issue encompasses the relationship between tourist flows and climate, and the 
tourism potential for a particular travel destination. Clarifying these three issues will generate climate information important to tourists and tourism authorities (Lin and Matzarakis 2008; Zaninovic and Matzarakis 2009; Matzarakis 2010; Matzarakis and Nastos 2011).

Several indices have been developed over the last 40 years to assess the suitability of climate for tourism activities (Morgan et al. 2000; Maddison 2001; Lise and Tol 2002; Gomez Martın 2004; Hamilton and Lau 2005; de Freitas et al. 2008; Lin and Matzarakis 2008; Zaninovic and Matzarakis 2009). A summary and short explanation of them is given in Abegg (1996) and Matzarakis (2006). The most widely known and applied index is the Tourism
Climate Index proposed by Mieczkowski (1985), which combines seven factors and parameters. Also, several methods based on the human energy balance exist for the calculation of thermal comfort (Fanger 1972; VDI 1998; Matzarakis 2006).

In order to include appropriate and modern methods, the physiologically equivalent temperature (PET), a thermal index derived from the human energy balance (Mayer and Höppe 1987; Höppe 1993, 1999; Taffé 1997) can be used. It is well suited to the evaluation of the thermal component of different climates. As well as having a detailed thermophysiological basis, PET is preferable to other thermal indices such as the predicted mean vote because

Fig. 1 Map of the Ourmieh Lake and selected stations

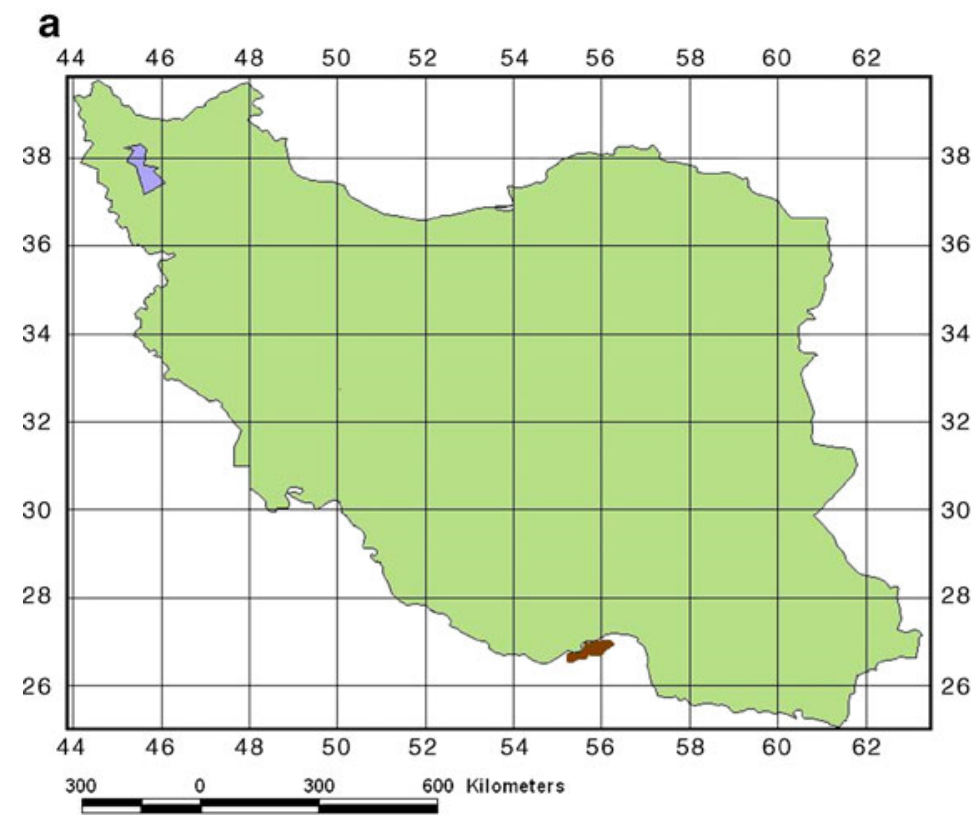

Lake Ourmieh Iran

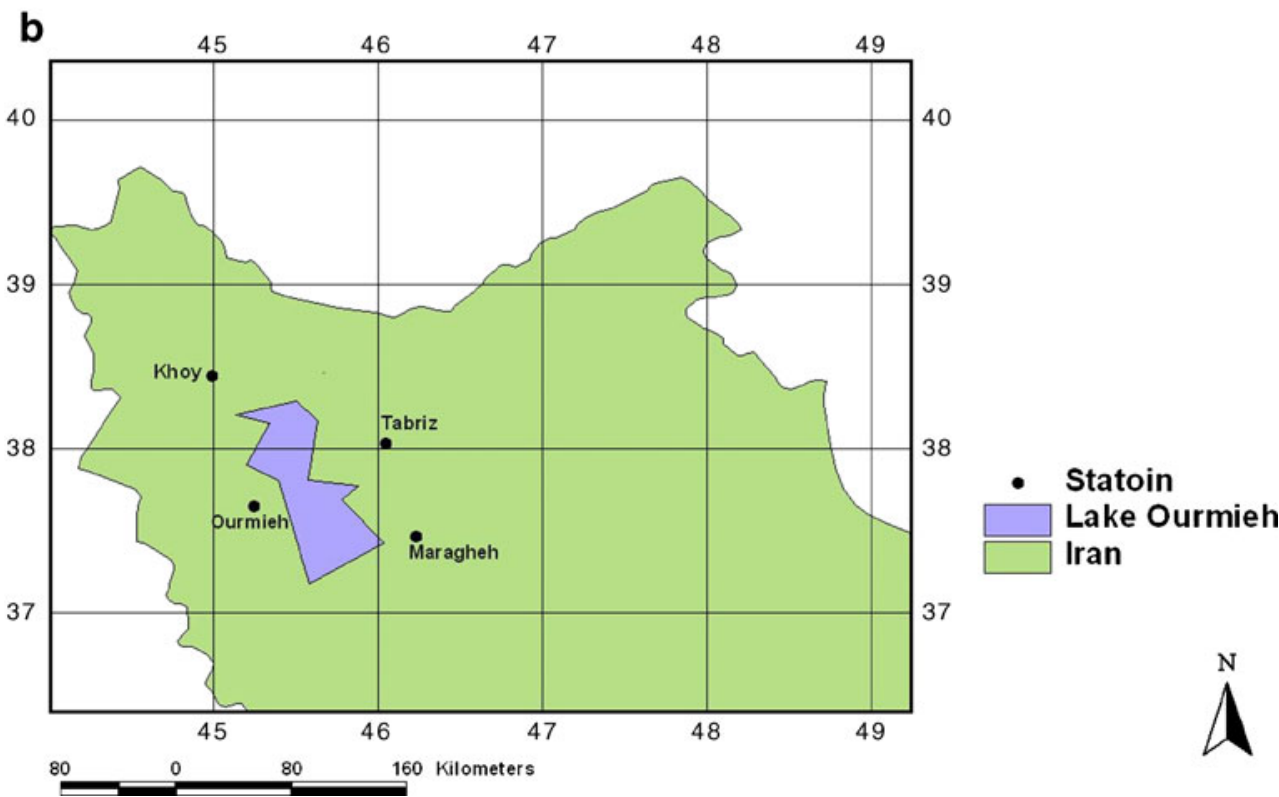


Table 1 Selected stations of Ourmieh Lake

\begin{tabular}{lcll}
\hline Station & Latitude $(\mathrm{N})$ & Longitude $(\mathrm{E})$ & Elevation $(\mathrm{m})$ \\
\hline Tabriz & $38.05^{\circ}$ & $46.17^{\circ}$ & 1,361 \\
Ourmieh & $37.32^{\circ}$ & $45.05^{\circ}$ & 1,313 \\
Khoy & $38.33^{\circ}$ & $44.58^{\circ}$ & 1,108 \\
Maragheh & $37.24^{\circ}$ & $46.14^{\circ}$ & 1,448 \\
\hline
\end{tabular}

of its units $\left({ }^{\circ} \mathrm{C}\right)$, which make results more comprehensible to urban or regional planners, for example, who are not so familiar with modern human-biometeorological terminology. PET results can be presented graphically or as bioclimatic maps. Graphs mostly display the temporal behavior of PET, whereas spatial distribution is specified in bioclimatic maps (Matzarakis et al. 1999).

The thermal bioclimate is of high interest for decision makers in the public health and recreation tourism sectors, as well as for the general public. The mapping of modern bioclimatic indices, based on the human energy balance, presents an adequate method for the quantification of the human thermal bioclimate that can be applied for different uses and requirements. The need for bioclimatic information for health tourism and for tourism and recreation in general is very high (Matzarakis et al. 2004a, b; Matzarakis 2006, 2010). Additional factors and detailed implementation of the climate relevant factors for tourism and recreation can performed with new tourism climate indices, e.g., Climate Tourism/Transfer Information Scheme (CTIS), which is based on frequencies of thresholds (Matzarakis 2007).

The main purpose of this paper is to determine human thermal comfort in Ourmieh Lake by cooling power, PET calculated by RayMan model and CTIS. The different methods are applied for the Ourmieh Lake because of the importance as a salt lake like the death sea.

\section{Study area}

The Ourmieh Lake is one of the largest and permanent lakes of Iran and has characteristics of its own. This lake is located in between the East Azarbaijan and West Azarbaijan provinces at $37^{\circ} 05^{\prime}-38^{\circ} 16^{\prime} \mathrm{N}$ and $45^{\circ} 10-45^{\circ} 45^{\prime} \mathrm{E}$ and at an elevation of $1,274 \mathrm{~m}$ (Fig. 1). Mean annual precipitation ranges from 400 to $600 \mathrm{~mm}$ and air temperature from -17 to $36^{\circ} \mathrm{C}$. The lake is saturated with salt which is said to help in the treatment of some diseases. Regarding the size, depth, chemical composition, sedimentation, ecology, water currents, and wild species, this lake bears special characteristics. It has been recorded as a National Park by the Department of the Environment and internationally as a Reserve Biosphere by the United Nations Educational, Scientific and Cultural Organization. The Ourmieh Lake has about 102 islands both large and small. Five of these islands can be noted here such as the Islands of Islami, Kaboodan, Ashk Daqi, Espir, and Arezoo. These come under the political and commercial sectors of the province. By virtue of its high levels of salinity, the lake does not sustain any fish. Nonetheless, Orumieh Lake is considered to be one of the largest natural habitats of Artemia, which serve as food source for the migratory birds such as flamingos (http://www.itto.org/provinces).

The study area attracted both domestic and foreign tourists during summer; and because of its unique characteristics, it can be one of the tourism big poles in northwest Iran. This potential cannot be achieved unless large and applied research in relation to tourism and climate is carried out. The goal of this study is to achieve and determine human thermal comfort and suitable period for tourism for recreational activities on the beach of the Ourmieh Lake by using meteorological parameter from meteorological stations Tabriz, Ourmieh, Khoy, and Maragheh (Table 1).

\section{Data and methods}

In this research, cooling power, PET, and CTIS have been applied. Monthly mean data on air temperature, relative humidity, total precipitation, and total hours of sunshine and average wind velocity for the period 1985-2005 were obtained from Iran Meteorological Organization for Ourmieh Lake (Table 1).
Table 2 Cooling power of environment and bioclimatic limits on the basis of cooling power

Source: Jahanbakhsh (1998)

\begin{tabular}{lll}
\hline Environment cooling power & Air situation & Type of bioclimatic stimulation \\
\hline $0-4$ & Hot-sultry-uncomfortable & Bioclimatic pressure \\
$5-9$ & Warm-comfortable & Bioclimatic comfort \\
$10-19$ & Mild-pleasant & Bioclimatic comfort \\
$20-29$ & Cool & Moderate stimulation \\
$30-39$ & Cold-slightly uncomfortable & Middle to intense stimulation \\
$40-49$ & Moderate-very uncomfortable & Presser in middle aspect \\
$50-59$ & Unpleasant-extremely cold & Intensive pressure \\
\hline
\end{tabular}




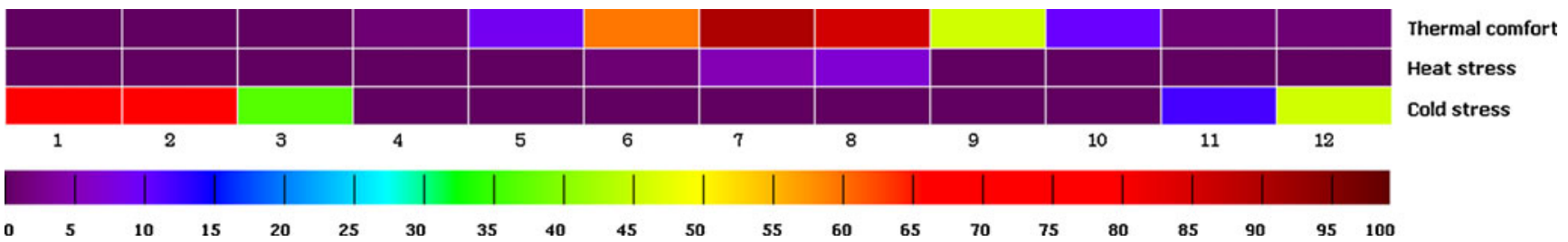

Fig. 2 Explanation of the Climate Tourism/Transfer Information Scheme (CTIS); see also text

The selection of cooling power has been done because of the simplicity and the combination of air temperature and wind speed and the description of effects of cold climates. Becker (1972) used the following equation for the calculation of cooling power:

$$
\begin{aligned}
\text { Cooling power }(\mathrm{CP})= & \left(0.26+0.34 \times v^{0.622}\right) \\
& \times(36.5-\mathrm{Ta}) \mathrm{Mcal} / \mathrm{cm}^{2} / \mathrm{s}
\end{aligned}
$$

In this equation, $v$ is wind speed $(\mathrm{m} / \mathrm{s})$ and $T$ is average air temperature $\left({ }^{\circ} \mathrm{C}\right)$. According to this method, if $\mathrm{CP}$ less than 10 , it will cause bioclimatic unpleasantness and undesirable conditions because of high air temperature. If CP is more than 20, due to extreme cold conditions, it will cause a mild stimulation and no thermal comfort.

In Eq. 1, cooling power in relation to a given difference between body, air temperature, and wind velocity shown in micro calorie per square centimeter per second. Table 2 shows cooling power and human bioclimate stimulation thresholds based on Becker method (Becker 1972; Jahanbakhsh 1998).

The traditional climatic indices have several weaknesses. From a climatology point of view, they do not include the effects of short- and long-wave radiation fluxes, since these are generally not included in climatic records (Matzarakis et al. 2004a, b; Matzarakis 2006). In addition, the concept is only for summer tourism and they do not include appropriate assessments for the thermal facet, based on human energy balance of humans. Another point is the lack of information about extremes or extreme events.

Commonly used indices quantifying the effect of the thermal environment on humans are predicted mean vote, PET, and standard effective temperature. The advantage of any of these three thermal indices is that they can evaluate the thermal conditions year round: they require input from the same meteorological variables (air temperature, air humidity, wind speed, and short- and longwave radiation fluxes) and they can be calculated with free software packages, e.g., RayMan (Matzarakis et al. 2007a, b). In this study, PET is used due to its widely known unit, ${ }^{\circ} \mathrm{C}$, as an indicator of thermal stress and/or comfort. This easily understood unit is of particular importance for users such as planners and policy makers, who most likely are unfamiliar with human biometeorological terminology (Matzarakis
2007; Lin and Matzarakis 2008, Zaninovic and Matzarakis 2009). In order to calculate PET on Ourmieh Lake using the RayMan model (Matzarakis et al. 2007a, 2010), the following variables were included in the model: air temperature, vapor pressure, average wind speed, and global radiation.

For a graphical description of analyzed tourism-related parameters, a useful method is the CTIS (Matzarakis 2007; Lin and Matzarakis 2008; Matzarakis et al. 2007b; Zaninovic and Matzarakis 2009) that provides all-seasonal frequency classes and frequencies of extreme weather events on a 10-day or monthly time scale (Matzarakis 2007). This method is preferred for analyzing climate stations or grid points. The analyzed bioclimatic parameters are presented in frequencies on a percentage basis. The interpretation of CTIS is described in Fig. 2. Each colored column describes the corresponding frequency of a parameter. A frequency of $100 \%$ indicates that each day in a month is characterized by the respective condition listed on the right hand side. A frequency of $50 \%$ corresponds to an occurrence of the indicated condition during 15 days, $10 \%$ to 3 days of the considered month, etc. Considering the first row, thermal comfort occurs from April to September with an average frequency of about $40 \%$ meaning that approximately 12 days are characterized by thermal comfort (Endler et al. 2010).

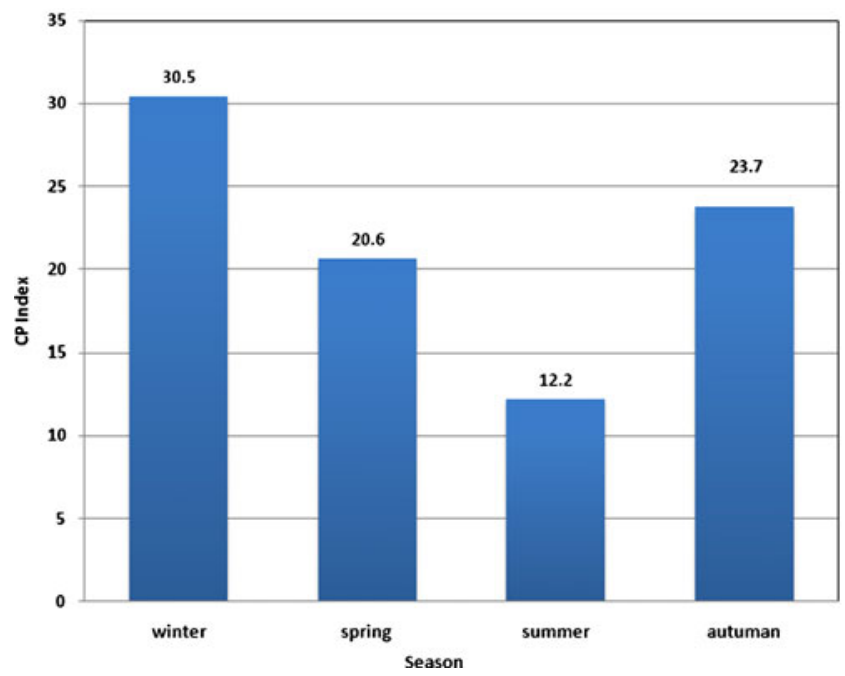

Fig. 3 Seasonal CP values in Ourmieh Lake for 1985-2005 


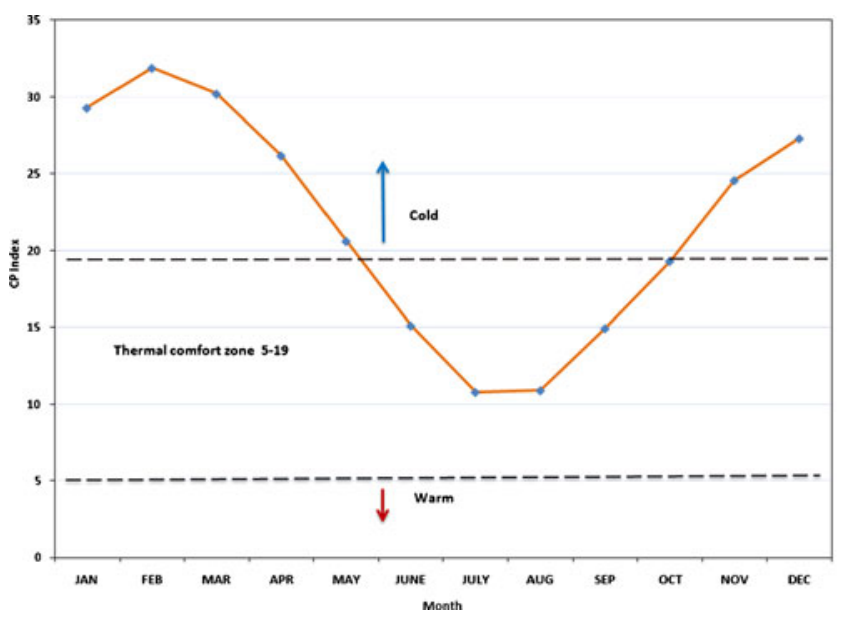

Fig. 4 Annual variation of CP in Ourmieh Lake for 1985-2005

One of the latest possibilities and tools in studying the relationship between tourism and climate, is the CTIS based on thermal, physical, and aesthetical aspects (Fig. 8; Lin and Matzarakis 2008; Matzarakis et al. 2007a, b). The thermal aspects include thermal acceptability (PET between $18^{\circ} \mathrm{C}$ and $29^{\circ} \mathrm{C}$ ), heat stress $\left(\mathrm{PET}>35^{\circ} \mathrm{C}\right.$ ), and cold stress $\left(\mathrm{PET}<0^{\circ} \mathrm{C}\right.$ ). The physical aspects include sultriness (when the vapor pressure more than $18 \mathrm{hPa}$ ), dry days (precipitation, $<1 \mathrm{~mm}$ ), wet days (precipitation, $>5 \mathrm{~mm}$ ) and windy parameter (wind speed, $>8 \mathrm{~m} / \mathrm{s}$ ). The aesthetical facet include for example sunshine (cloudiness, $<5$ octas), and fog (relative humidity, $>93 \%$ ).

This additional analysis requires data on precipitation, sunshine duration hours, and cloud cover.

\section{Results}

\subsection{Cooling power}

Based on CP results, the most appropriate time for tourism in the Ourmieh Lake is June through October. July and August are months with the CP value, $11 \mathrm{Mcal} / \mathrm{cm}^{2}$ and it is show well comfort conditions, but the months February and March which has CP value of 32 and $30 \mathrm{Mcal} / \mathrm{cm}^{2}$, respectively, have the most bioclimatic stress on human in the region. Figure 3 show that period summer with $\mathrm{CP}$ $12 \mathrm{Mcal} / \mathrm{cm}^{2}$ has the most favorable climatic conditions for tourist attractiveness in Ourmieh Lake. Winter with amount of CP $30 \mathrm{Mcal} / \mathrm{cm}^{2}$ shows extreme cold conditions and more bioclimatic stress on human, this season is not appropriate for tourism and recreation activities (Fig. 4 and Table 2).

\subsection{Physiologically equivalent temperature}

Human comfortable sensation cannot be identified only through the study of one climatic element but through combination of several elements. The PET which describes the effect of the thermal environment on humans is shown in Fig. 5 as a bioclimate diagram (Matzarakis 2007). Cold stress $\left(\mathrm{PET}<4^{\circ} \mathrm{C}\right)$ can be found in Ourmieh Lake in the period from the end of October to the beginning of April with the highest percentages of days in February (about 96\%). The lowest PET values were in January; this corresponds with the lowest air temperatures. Thermal comfort conditions do not exist during the main winter months. However, heat stress $\left(\mathrm{PET}>23^{\circ} \mathrm{C}\right)$ is observed from
Fig. 5 Thermal bioclimate diagram of physiologically equivalent temperature (PET) in Ourmieh Lake for 1985-2005 (see Table 3 for details)

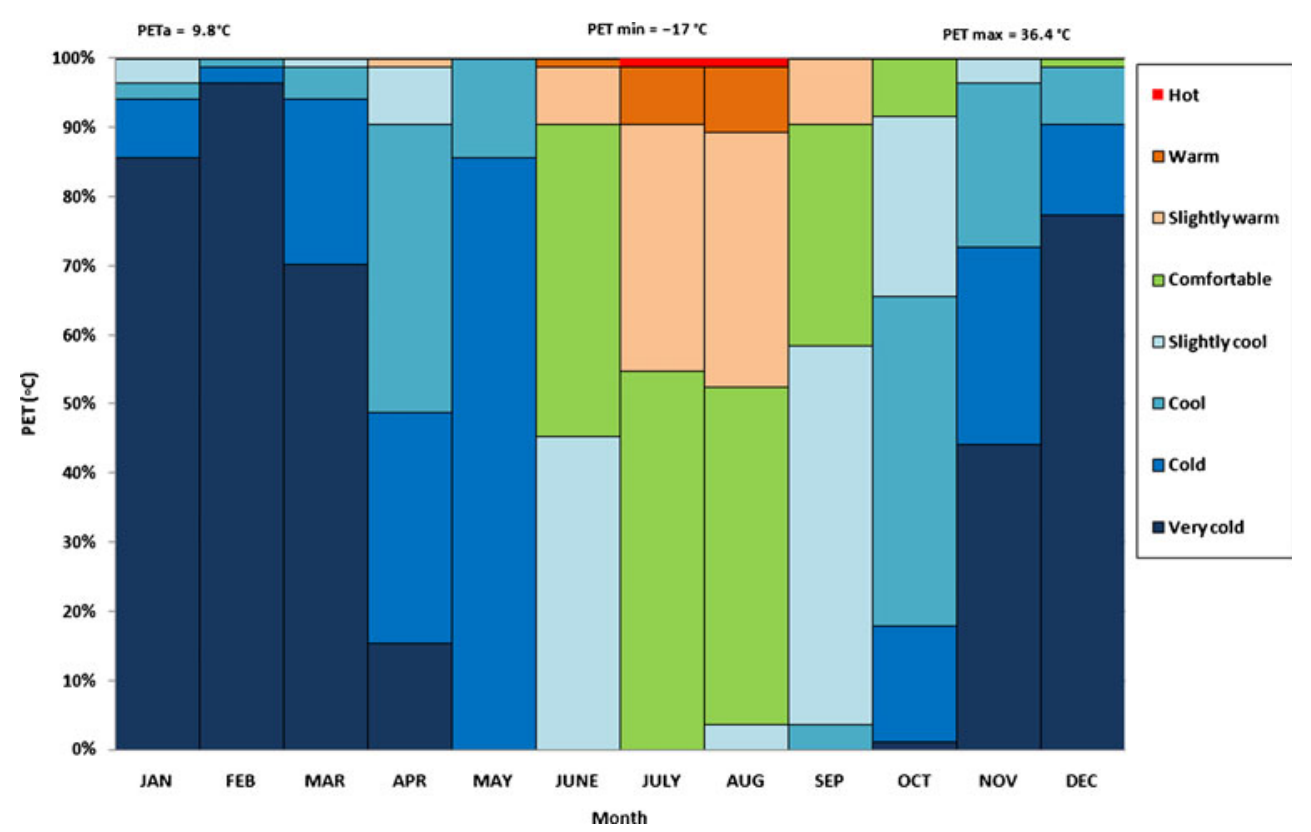


Table 3 Thermal sensation and PET classes for Ourmieh Lake

\begin{tabular}{llll}
\hline PET $\left({ }^{\circ} \mathrm{C}\right)$ & Thermal perception & PET $\left({ }^{\circ} \mathrm{C}\right)$ & Thermal perception \\
\hline$<4$ & Very cold & $18-23$ & Comfortable \\
$4-8$ & Cold & $23-29$ & Slightly warm \\
$8-13$ & Cool & $29-35$ & Warm \\
$13-18$ & Slightly cool & $35-41$ & Hot \\
\hline
\end{tabular}

Source: Matzarakis et al. (1999)

June to early October. The highest values of PET were in the beginning of June, although the warmest month based on the air temperatures is July. Based on the above description, the months June, July, August, and September, according to Table 3 are in comfortable physiological strain class. The results of this study clearly show these months are the most suitable for tourism and tourist activities.

Additionally, in this region, the mean PET is $9.8^{\circ} \mathrm{C}$, the absolute maximum is $36.4^{\circ} \mathrm{C}$ and minimum $-17^{\circ} \mathrm{C}$. In addition, the monthly minimum, maximum, and mean PET are presented in Fig. 6. The results show that thermal comfort in Ourmieh Lake was found in the summer months (July and August). The worst bioclimatic comfort conditions occur in the winter and autumn.

The variation of annual and seasonal means of PET Fig. 7 shows interesting characteristics. The greatest decrease is in autumn. PET value was $21.6^{\circ} \mathrm{C}$ in summer and $13.4^{\circ} \mathrm{C}$ in spring. Therefore from these values (Fig. 6), it can be realized that the optimum thermal comfort conditions and bioclimatic are in spring and summer season because PET values in these two seasons is more than the annual mean $\left(9.8^{\circ} \mathrm{C}\right)$. Autumn and winter seasons, with the value $5.7^{\circ} \mathrm{C}$ and $-1.2^{\circ} \mathrm{C}$, respectively, have the most worst bioclimatic conditions.
According to Fig. 8, the acceptable air temperature with frequency $60 \%, 86 \%$, and $91 \%$ occurs in the months June, July, and August, respectively. Cold stress $\left(\mathrm{PET}<0^{\circ} \mathrm{C}\right)$ was observed from December to March. The highest number of sunny days occurred from June to October.

\section{Discussion}

In our analysis, thermal comfort conditions influencing tourism are analyzed to determine possible thermal perceptions during different seasons by utilizing $\mathrm{CP}$ and PET for tourists. PET uses the majority of climatic elements affecting thermal comfort also the unit is based on ${ }^{\circ} \mathrm{C}$ which is easy to understand for tourists and ordinary people. In addition, the results of this study show the performance of this index in the evaluation of human thermal comfort. Most researches to date applied by climatologists use PET to indicate the ability of this method in determining the tourism period (Matzarakis 2006, 2010; Lin and Matzarakis 2008; Zaninovic and Matzarakis 2009).

The findings of this study are valuable for tourism in Ourmieh Lake. The results based on cooling power indicated that in Ourmieh Lake, the most favorable time for tourism is between June and October, e.g., about 153 days of the year during the period of this study is existing thermal comfort. The highest values occur during the summer and this issue is relevant of tourists for swimming in Ourmieh Lake is very favorable. PET values for this lake between June and September are suitable for tourism, sporting, and recreational activities. With regards to PET results, the thermal comfort (in the "comfortable" class) at Ourmieh Lake was found in June (45\%), July (55\%), August (49\%), and September (32\%), respectively.
Fig. 6 Annual variation of maximum, minimum, and mean PET in Ourmieh Lake for 1985-2005

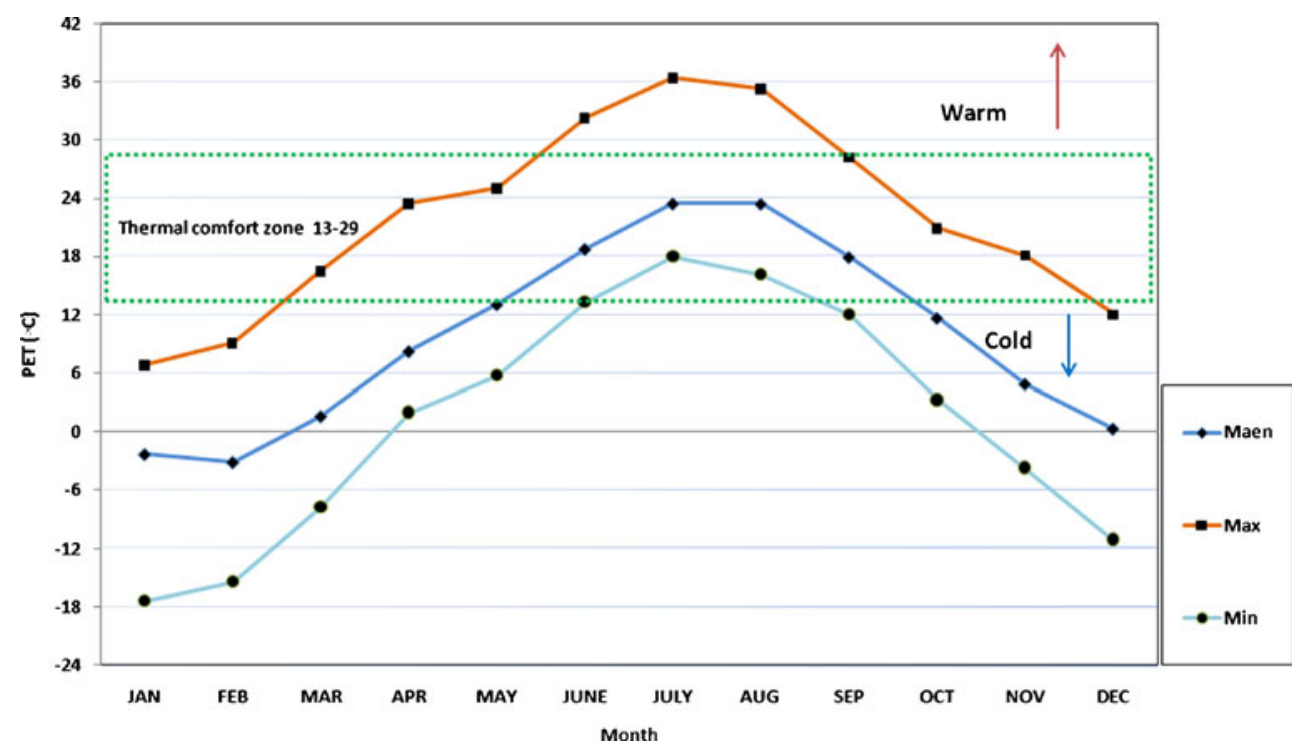


Fig. 7 Mean annual and seasonal values PET and linear trends for Ourmieh Lake for 1985-2005

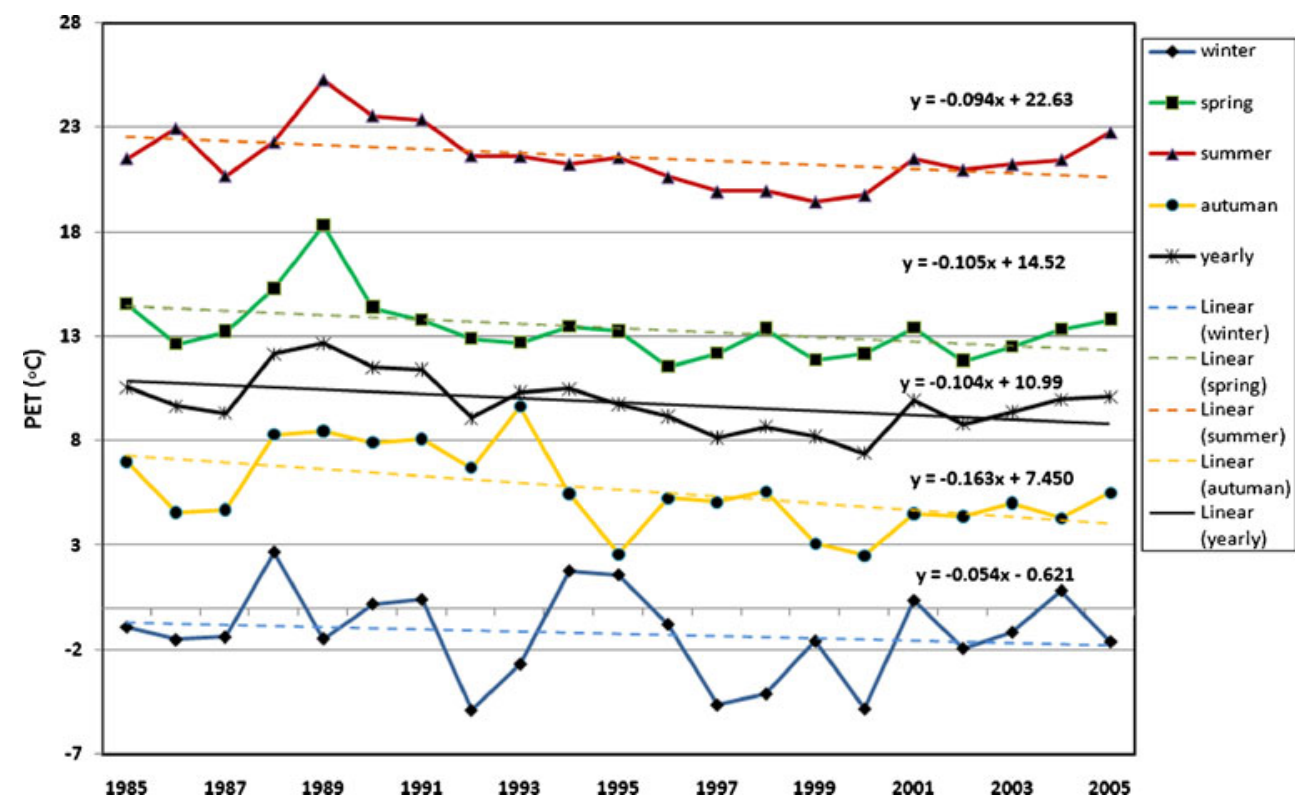

Our results show that the most favorable bioclimatic comfort conditions occur in summer. Cold stress (PET $<0^{\circ}$ C) was quantified from December to March. Sunny days occurred between June and October.

Many of the climate indices are only based on air temperature and air humidity; they do not include thermal comfort or thermal stress conditions based on the human energy balance. Furthermore, they are either formulated on a monthly basis or they can be used only for the summer months. Thus, they cannot be used for analysis of detailed weather and tourism relationships (Matzarakis 2006; Lin and Matzarakis 2011). For this reason, CP is limited in application for comprehensive thermal bioclimate studies.

The PET not only provides an integrated index for thermal environment but also allows tourists to predict their thermal perception of weather conditions. Therefore, it is important to analyze the characteristics of thermal adaptation and comfort range of residents from different regions to adequately describe the perception of people from different regions (Lin and Matzarakis 2008). Furthermore, PET is more understandable for tourists who can assess the outdoor thermal condition based on their experience in an indoor environment, as it has units of ${ }^{\circ} \mathrm{C}$ (VDI 1998; Matzarakis 2006).

For the assessment of weather and climate in tourism regions the CTIS has been developed. CTIS represents frequencies, probabilities, and thresholds of tourism climatic and bioclimatic factors. In addition, CTIS is a software that can operate this relevant data from text-based files and generate highly customizable diagrams. It can easily be used and implemented for diverse applications, i.e., decision making or information about tourism industry (Matzarakis 2007; Lin and Matzarakis 2008).

CTIS can be used on a 10- or 30-day time scale on a percentage basis. Although the 10-day interval is more convenient for tourism climate analysis. Because of the lack of daily data, we applied the monthly time scale.

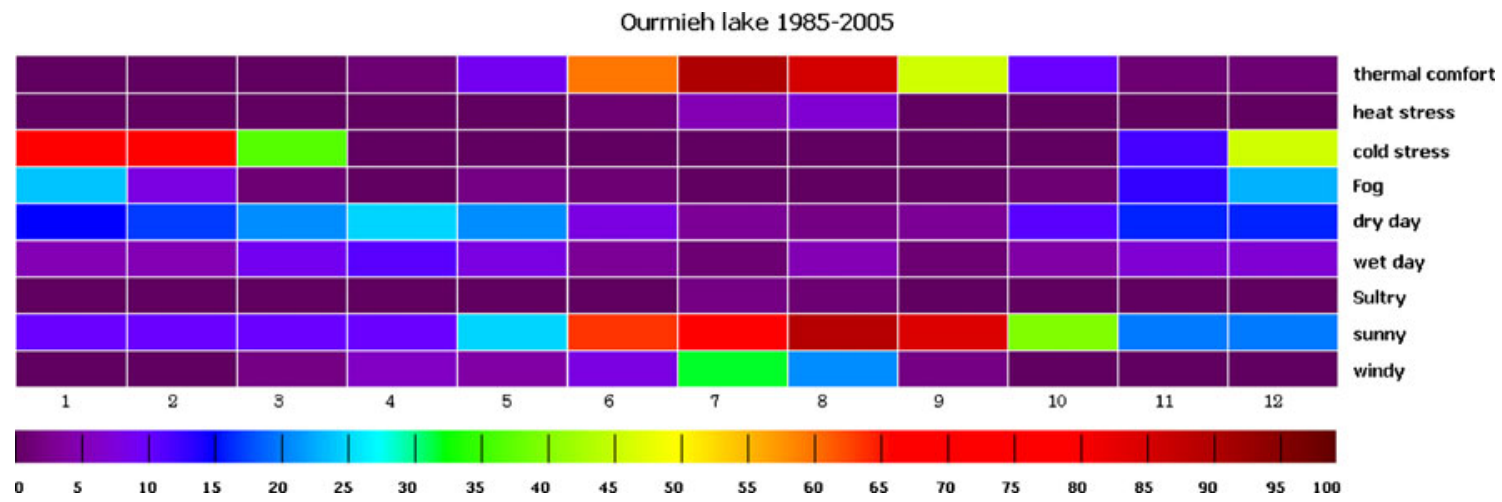

Fig. 8 The assessment of the Climate Tourism/Transfer Information Scheme (CTIS) for Ourmieh Lake for 1985-2005 


\section{Conclusion}

In this paper, we analyzed thermal comfort conditions for Ourmieh Lake. Meteorological stations Tabriz, Maragheh, Orumieh, and Khoy were used for the period 1985-2005. In this study, cooling power was used for comparison with PET. The results show that PET provides more appropriate information about the environmental thermal conditions because it combines air temperature, humidity, wind speed, and cloud cover. Therefore, PET reflects the atmospheric environment conditions better than cooling power or other methods. Cold stress $\left(\mathrm{PET}<4^{\circ} \mathrm{C}\right)$ occurs in Ourmieh Lake from the end of October to the beginning of April with the highest percentage (of about 96\%) in February. Heat stress $\left(\mathrm{PET}>23^{\circ} \mathrm{C}\right)$ is observed from June to early October. Therefore, the months of June, August, September, and July are the most suitable period for tourism and recreation activities. The additional implementation of other parameters shown with the CTIS builds a comprehensive information possibility and acts as a destination analysis for this specific region.

The Ourmieh Lake is the second salty lake in the world after the Death Sea. In contrast to the Death Sea, with much higher heat stress conditions, the Ourmieh Lake can be visited and attracted because of the high frequency of cold conditions, which can be used for cold climate therapeutically effects, higher attention, and visitors. The high potential of the lake possibly can attract many tourists and in accordance the provided results show the best time of thermal comfort on the shores of Lake Ourmieh. For optimum enjoyment, the environment potential in the region should be included in the planning process of the different regions and parts of the seas. Iran country attracts tourists to the area and causes an economic development. The awareness of climate tourism information is the basis for pursuing a successful strategy in tourism industry.

Open Access This article is distributed under the terms of the Creative Commons Attribution Noncommercial License which permits any noncommercial use, distribution, and reproduction in any medium, provided the original author(s) and source are credited.

\section{References}

Abegg B (1996) Klimaänderung und Tourismus. Schlussbericht NFP 31. vdf Hochschulverlag AG an der ETH: Zürich

Becker F (1972) Bioklimatische Reizstufen für eine Raumbeurteilung zur Erholung, Forschungs- und Sitzungsberichte der Akademie für Raumforschung und Landesplanung Hannover $76: 45-61$
De Freitas CR, Scott D, McBoyle G (2008) A second generation climate index for tourism (CIT): specification and verification. Int J Biometeorol 52:399-207

Endler C, Oehler K, Matzarakis A (2010) Vertical gradient of climate change and climate tourism conditions in the Black Forest. Int $\mathrm{J}$ Biometeorol 54:45-61

Fanger PO (1972) Thermal comfort. McGraw Hill, New York

Gomez Martın MB (2004) An evaluation of the tourist potential of the climate in Catalonia (Spain): a regional study. Geografska Annaler 86A:249-264

Hamilton J, Lau M (2005) The role of climate information in tourist destination choice decision-making. In: Gossling S, Hall CM (eds) Tourism, recreation and climate change. Routledge, London, pp 229-250

Höppe P (1993) Heat balance modelling. Experientia 49:741-746

Höppe P (1999) The physiological equivalent temperature - a universal index for the biometeorological assessment of the thermal environment. Int J Biometeorol 43:71-75

Jahanbakhsh S (1998) Assessment Environmental of human climate Tabriz and thermal requirements of building, geographic. Research Quarterly, No, 48

Lin TP, Matzarakis A (2008) Tourism climate and thermal comfort in Sun Moon Lake, Taiwan. Int J Biometeorol 52:281-290

Lin TP, Matzarakis A (2011) Tourism-climate information based on human thermal perception in Eastern China and Taiwan. Tour Manag 32:492-500

Lise W, Tol RSJ (2002) Impact of climate on tourism demand. Clim Change 55:429-449

Maddison D (2001) In search of warmer climates? The impact of climate change on flows of british tourists. Clim Change 49:193-208

Matzarakis A (2006) Weather and climate related information for tourism. Tour Hosp Plan Dev 3:99-115

Matzarakis A (2007) Entwicklung einer Bewertungsmethodik zur Integration von Wetter- und Klimabedingungen im Tourismus. Ber Met Inst Univ Freiburg 16:73-79

Matzarakis A (2010) Climate Change: Temporal and spatial dimension of adaptation possibilities at regional and local scale. In: Schott $\mathrm{C}$ (ed) Tourism and the implications of Climate Change: Issues and Actions, Emerald Group Publishing. Bridging Tourism Theory and Practice 3:237259

Matzarakis A, Mayer H, Iziomon M (1999) Heat stress in Greece. Applications of a universal thermal index: physiological equivalent temperature. Int J Biometeorol 43:76-84

Matzarakis A, de Freitas C, Scott D (eds) (2004) Advances in Tourism Climatology. Berichte des Meteorologischen Institutes der Universität Freiburg Nr. 12

Matzarakis A, Zygmuntowski M, Koch E, Rudel E (2004) Mapping the thermal bioclimate of Austria for recreation tourism. In: Matzarakis A, de Freitas C, Scott D (eds) Advances in tourism climatology. Ber Meteorol Inst Univ Freiburg Nr 12, 10-18

Matzarakis A, Rutz F, Mayer H (2007a) Modelling Radiation fluxes in simple and complex environments - application of the RayMan model. Int J Biometeorol 51:323-334

Matzarakis A, Matuschek O, Neumcke R, Rutz F, Zalloom M (2007b) Climate change scenarios and tourism - how to handle and operate with data. In: Matzarakis A, de Freitas CR, Scott D (eds) Developments in tourism climatology, pp 240-245

Matzarakis A, Rutz F, Mayer H (2010) Modelling Radiation fluxes in simple and complex environments - Basics of the RayMan model. Int J Biometeorol 54:131-139

Mayer H, Höppe P (1987) Thermal comfort of man in different urban environments. Theor Appl Climatol 38:43-49 
Mieczkowski Z (1985) The tourism climate index: a method for evaluating world climates for tourism. Can Geogr 29:220 233

Morgan R, Gatell E, Junyent R, Micallef A, Özhan E, Williams A (2000) An improved user-based beach climate index. J Coast Conserv 6:41-50

Matzarakis and Nastos (2011) Analysis of tourism potential for Crete Island, Greece. Global Nest Journal, in press
Taffé P (1997) A qualitative response model of thermal comfort. Build Environ 32:115-121

VDI (1998) Methods for the human biometeorological evaluation of climate and air quality for the urban and regional planning. Part I: Climate. VDI guildline 3787. Part 2. Beuth, Berlin

Zaninovic K, Matzarakis A (2009) The Biometeorological Leaflet as a means conveying climatological information to tourists and the tourism industry. Int J Biometeorol 53:369-374 